\title{
Influence of rising tide and falling tide on settling process of Cd in Jiaozhou Bay
}

\author{
Dongfang Yang ${ }^{1,2,3 \text {, a } \text {, Chunhua Su}}{ }^{1,2}$, Yunjie Wu ${ }^{1,2}$, Zhikang Wang ${ }^{1,2}$, and Sixi Zhu ${ }^{1,2}$ \\ ${ }^{1}$ Research Center for Karst Wetland Ecology, Guizhou Minzu University, Guizhou Guiyang, Guizhou \\ Guiyang, China \\ ${ }^{2}$ College of Chemistry and Environmental Science, Guizhou Minzu University, Shanghai, 550025, China \\ ${ }^{3}$ North China Sea Environmental Monitoring Center, SOA, Qingdao 266033, China \\ adfyang_dfyang@126.com
}

Keywords: Cadmium (Cd), settling process, rising tide, Falling tide, Jiaozhou Bay.

\begin{abstract}
Settling is one of the important transporting processes of pollutants in marine bay. Based on the analysis on the distributions of Cd in bottom waters in Jiaozhou Bay 1988, this paper defined the settling process. Results showed that Cd contents in bottom waters in Jiaozhou Bay in April and July 1988 were $0.08-0.10 \mu \mathrm{g} \mathrm{L}^{-1}$ and $0.09-0.61 \mu \mathrm{g} \mathrm{L}^{-1}$, respectively, indicated that the pollution level of Cd in bottom waters in this bay was still very slight in 1988. By means of vertical water's effect, there were high settling regions from the bay mouth to the bay center in April 1988, and there were high settling regions in the inner side of the bay mouth in July 1988. By means of rising tide and falling tide, Cd from different sources was settling the moving path, resulting in high settling regions along with the moving path. As a result, during the settling process of Cd, drifting phenomenon was occurring.
\end{abstract}

\section{Introduction}

$\mathrm{Cd}$ is not a essential element for human, and the content of $\mathrm{Cd}$ in the environment is always very low, and is not harmful to human in normal condition. However, the exploit and use of Cd in increasing along with the rapid increasing of industry, resulting in the excessive existence of Cd in the environment, and risks to human and ecosystem, since $\mathrm{Cd}$ in one of the toxic heavy metal elements [1-3]. Many marine bays have been polluted by Cd since ocean is the sink of pollutants, and understanding the migration process of $\mathrm{Cd}$ is essential to environmental remediation [4-7].

Settling is one of the key migration processes of pollutants in marine bays by means of vertical water's effect [8-10], and is resulting in the variations of Cd contents in bottom waters. Jiaozhou Bay is a semi-closed bay located in Shandong Province, China, and has been polluted by various pollutants including $\mathrm{Cd}$ in the past decades [1-4]. Based on investigation on Cd in bottom waters in April and July 1988 in Jiaozhou Bay, this paper is to identify the settling of Cd, and to provide basic information for pollution control.

\section{Study area and data collection}

Jiaozhou Bay is located in the south of Shandong Province, eastern China $\left(35^{\circ} 55^{\prime}-36^{\circ} 18^{\prime} \mathrm{N}\right.$, $120^{\circ} 04^{\prime}-120^{\circ} 23^{\prime} \mathrm{E}$ ), with the total area and average water depth of $446 \mathrm{~km}^{2}$ and $7 \mathrm{~m}$, respectively. The bay mouth is very narrow $(3 \mathrm{~km})$, and is connected to the Yellow Sea. There are a dozen of rivers including Dagu River, Haibo Rriver, Licun Rriver, and Loushan Rriver etc., all of which are seasonal rivers [11-12]. The investigation on Cd in bottom waters in Jiaozhou Bay was carried on in April and July 1988. In April and July, there were 6 monitoring sites (i.e., 34, 35, 36, 84, 85, 89 and 90) (Fig. 1). Cd in waters was sampled and monitored follow by National Specification for Marine Monitoring [13]. 


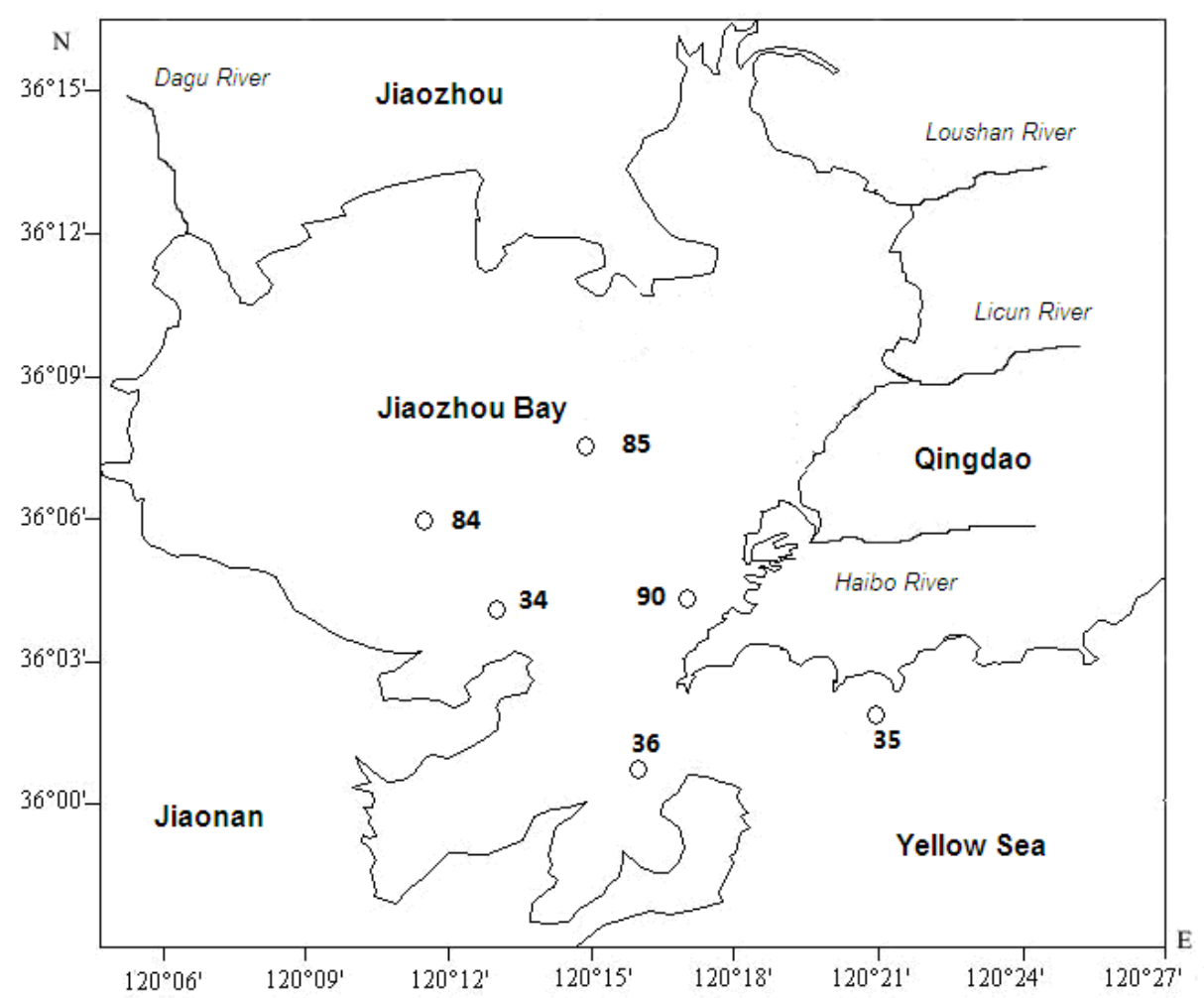

Fig. 1 Geographic location and sampling sites of Jiaozhou Bay

\section{Results and discussion}

\subsection{Contents and pollution level of $\mathrm{Cd}$ in bottom waters.}

Cd contents in bottom waters in Jiaozhou Bay in April, and July 1988 were $0.08-0.10 \mu \mathrm{g} \mathrm{L}^{-1}$ and 0.09-0.61 $\mu \mathrm{g} \mathrm{L}^{-1}$, respectively (Table 1). In according Sea Water Quality Standard (GB3097-1997), the pollution levels of Cd in bottom waters Jiaozhou Bay in 1988 were still very slight. April and July were spring and summer in study area. It could be found that Cd contents in Jiaozhou Bay were in order of summer>spring. This indicated that the seasonal variations of Cd was significant.

Table 1 Cd contents and pollution levels in bottom waters in Jiaozhou Bay 1988

\begin{tabular}{ccc}
\hline Month & April & July \\
\hline $\mathrm{Cd} \mathrm{content} / \mu \mathrm{g} \mathrm{L}^{-1}$ & $0.08-0.10$ & $0.09-0.61$ \\
Grade & $\mathrm{I}$ & $\mathrm{I}$ \\
\hline
\end{tabular}

\subsection{Horizontal distributions of $\mathrm{Cd}$ in bottom waters.}

In April 1988, the contour lines of Cd contents were forming a serious parallel lines, and were decreasing gradiently from the internal waters inside the bay $\left(0.10 \mu \mathrm{g} \mathrm{L}^{-1}\right)$ to the bay mouth, and to the open waters $\left(0.08 \mu \mathrm{g} \mathrm{L}^{-1}\right)$ (Fig. 2). In July 1988, high value $\left(0.61 \mu \mathrm{g} \mathrm{L}^{-1}\right)$ of Cd contents in bottom waters was occurring in Site 34 in the coastal waters in the southwest of the bay, and the contour lines of $\mathrm{Cd}$ contents were forming a serious semi-cycles, and $\mathrm{Cd}$ contents were decreasing from the high value center to the center of the bay $\left(0.09 \mu \mathrm{g} \mathrm{L}^{-1}\right)$ (Fig. 3). In according to the horizontal distributions of $\mathrm{Cd}$ in bottom waters, it could be found that there were high settling regions from the bay center to the bay mouth in April 1988, and was high settling regions in the inner side of the bay mouth. 


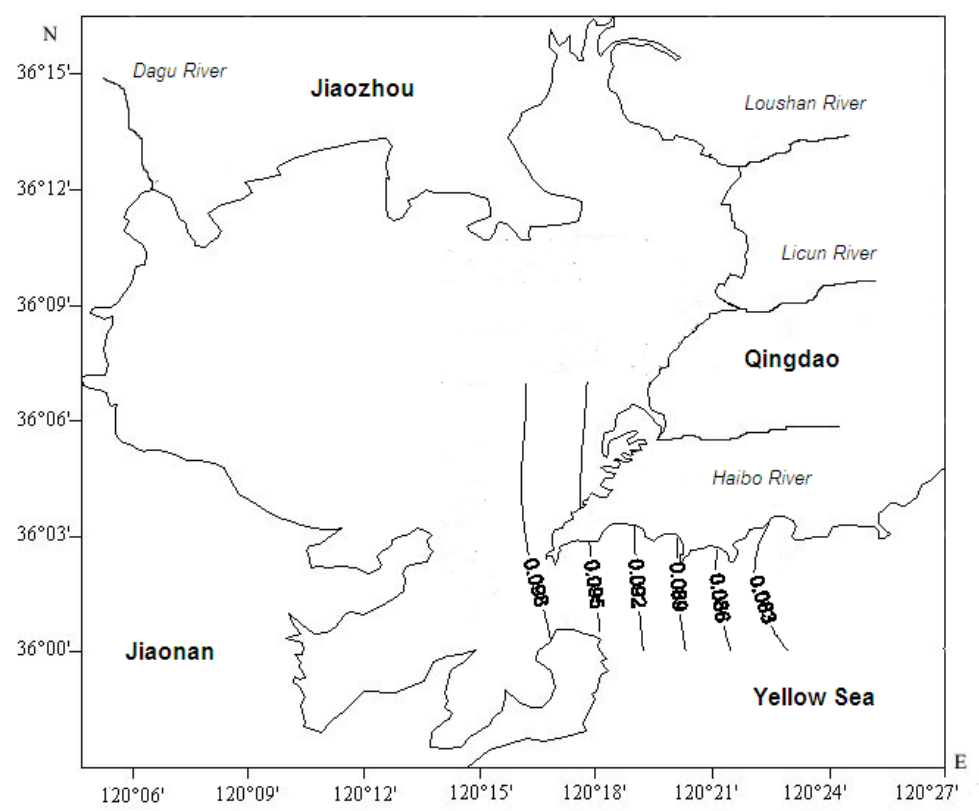

Fig. 2 Horizontal distribution of Cd in bottom waters in Jiaozhou Bay in April $1988 / \mu g \mathrm{~L}^{-1}$

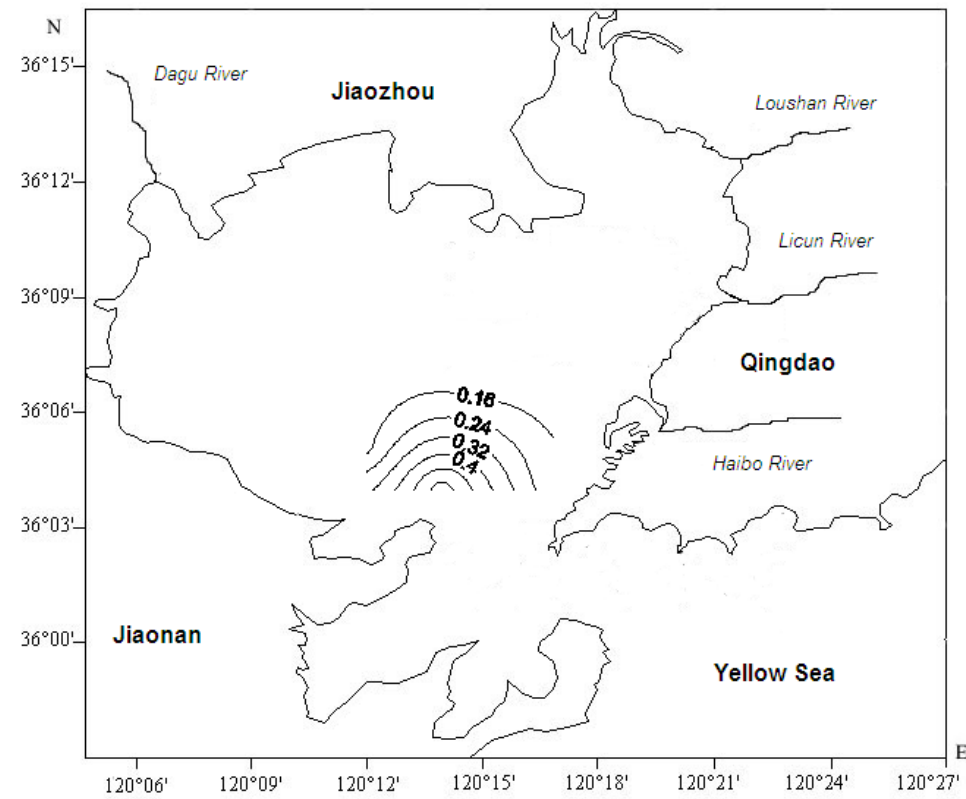

Fig. 3 Horizontal distribution of Cd in bottom waters in Jiaozhou Bay in July $1988 / \mu \mathrm{g} \mathrm{L}{ }^{-1}$

\subsection{Drifting during settling process of $\mathrm{Cd}$.}

The migration process of pollutant in marine bay is mainly determined bay source input and and hydrodynamic force. In April 1988, the major Cd source in Jiaozhou Bay was marine current, whose source strength was relative weak. By means of the input of Cd from marine current, as well as vertical water's effect, were high settling regions from the bay center to the bay mouth. During the settling process of $\mathrm{Cd}$, there was a drifting process from the outer side of the bay mouth to the bay mouth and the bay center. The reason was that while marine current was moving from the open waters to the internal waters via the bay mouth, and Cd was delivered to the bay mouth and the bay center, and was settling rapidly by means of vertical water's effect [8-10], and was resulting in high settling regions in these regions (Fig. 4). In July 1988, the major Cd source in Jiaozhou Bay was Haibo River, whose source strength was relative strong. By means of the input of Cd from marine current, as well as vertical water's effect, were high settling regions in the inner side of the bay mouth. During the settling process of $\mathrm{Cd}$, there was a drifting process from the estuary of Haibo 
River to the inner side of the bay. The reason was that while river flow was moving from the the river mouth to the bay mouth, and Cd was delivered to the bay mouth, and was settling rapidly by means of vertical water's effect [8-10], and was resulting in high settling regions in the inner side of the bay mouth (Fig.).

\subsection{Influence of tide on migration of $\mathrm{Cd}$.}

Tide is the major form of hydrodynamic force in ocean. In April 1988, Cd in Jiaozhou Bay was mainly supplied by marine current. During the rising tide, Cd was delivered by marine current from open waters to internal waters via the bay mouth, and a part of Cd was settling along with the flow direction of marine current by means of gravity force, resulting in high settling processes in the bay mouth and the bay center (Fig. 4). In July 1988, Cd in Jiaozhou Bay was mainly supplied by river flow. During the falling tide, Cd was delivered from the river mouth the bay mouth via the bay center, and a part of Cd was settling along with the flow direction of marine current by means of gravity force, resulting in high settling processes in the inner side of the bay mouth (Fig. 5). By means of rising tide and falling tide, Cd from different sources was settling an the moving path, resulting in high settling regions along with the moving path. Therefore, during the settling process of Cd, drifting phenomenon was occurring.

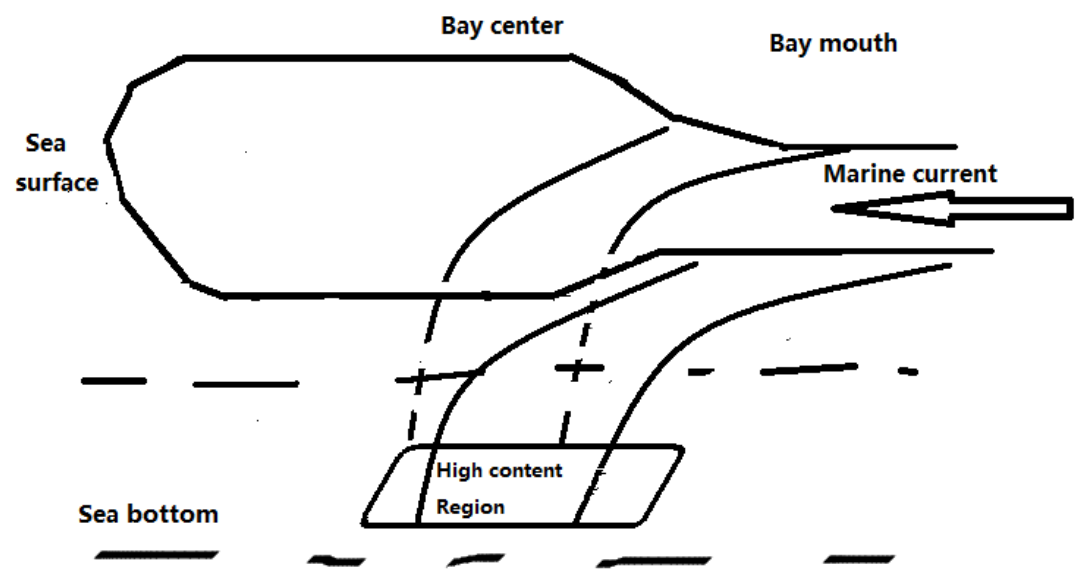

Fig. 4 The settling and drifting of Cd in case of marine current was the major Cd source in Jiaozhou Bay

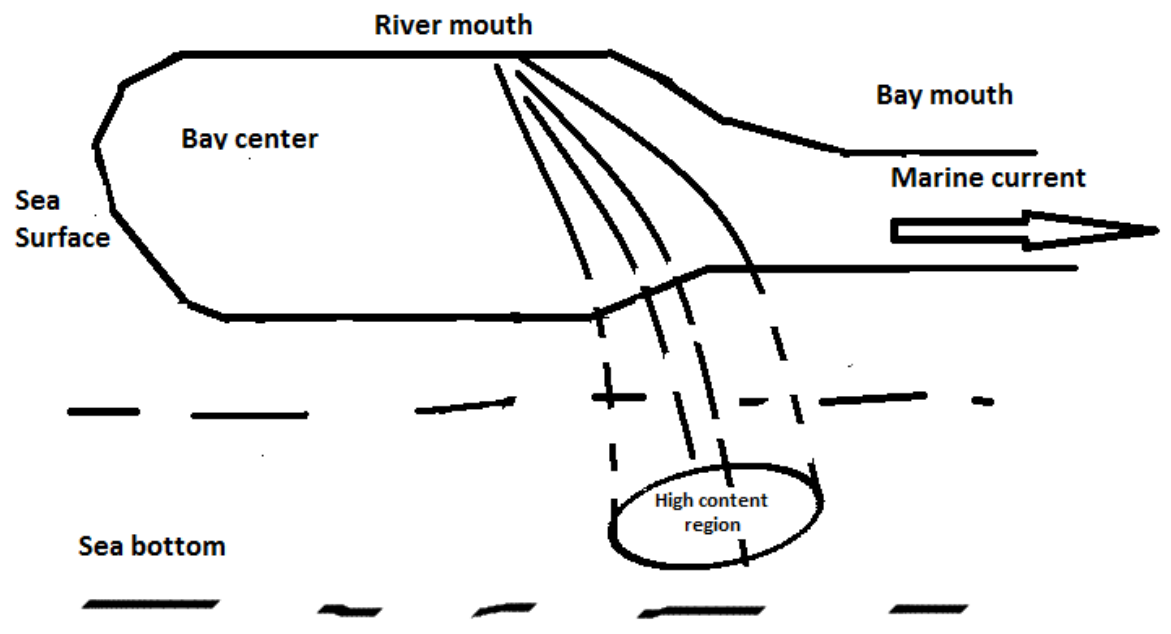

Fig. 5 The settling and drifting of Cd in case of river flow was the major Cd source in Jiaozhou Bay

\section{Conclusion}

Cd contents in bottom waters in Jiaozhou Bay in April and July 1988 were $0.08-0.10 \mu \mathrm{g} \mathrm{L}^{-1}$ and 0.09-0.61 $\mu \mathrm{g} \mathrm{L}^{-1}$, and the pollution level of Cd in bottom waters in this bay was still very slight in 
1988. There were high settling regions from the bay mouth to the bay center in April 1988, and there was high settling regions in the inner side of the bay mouth in July 1988. By means of rising tide and falling tide, Cd from different sources was settling an the moving path, resulting in high settling regions along with the moving path. As a result, during the settling process of Cd, drifting phenomenon was occurring.

\section{Acknowledgment}

This research was sponsored by the China National Natural Science Foundation (31560107), Doctoral Degree Construction Library of Guizhou Nationalities University and Research Projects of Guizhou Nationalities University ([2014]02), Research Projects of Guizhou Province Ministry of Education (KY [2014] 266), Research Projects of Guizhou Province Ministry of Science and Technology (LH [2014] 7376).

\section{References}

[1] Yang DF and Miao ZQ: Marine Bay Ecology (I): Beijing, Ocean Precess, (2010), p. 1-320. (in Chinese)

[2] Yang DF and Gao ZH: Marine Bay Ecology (II): Beijing, Ocean Precess, (2010), p. 1-330. (in Chinese)

[3] Yang DF, Chen Y, Wang H, et al.: Coastal Engineering, Vol. 29 (2010), p. 73-82.

[4] Yang DF, Chen Y, Liu CX, et al.: Coastal Engineering, Vol. 32(2013), p. 68-78.

[5] Yang DF, Zhu SX, Wu YF, et al.: Applied Mechanics and Materials, Vol.644-650 (2014), p. 5325-5328.

[6] Yang DF, Wang FY, Wu YF, et al.: Applied Mechanics and Materials, Vol.644-650 (2014), p. 5329-5312.

[7] Yang DF. Chen Y, Gao ZH, et al.: Proceedings of the 2015 international symposium on computers and informatics. Vol. (2015), p. 2667-2674.

[8] Yang DF, Wang FY, He HZ, et al.: Proceedings of the 2015 international symposium on computers and informatics, 2015, p. 2655-2660.

[9] Yang DF, Wang FY, Zhao XL, et al.: Sustainable Energy and Enviroment Protection, 2015, p.191-195.

[10] Yang DF, Wang FY, Yang XQ, et al.: Advances in Computer Science Research, Vol. 2352 92015), p. 198-204.

[11] Yang DF, Chen Y, Gao ZH, et al.: Chinese Journal of Oceanology and Limnology, Vol. 23(2005), p. 72-90. (in Chinese)

[12] Yang DF, Wang FY, Gao ZH, et al. Marine Science, Vol. 28 (2004), p. 71-74. (in Chinese)

[13] China's State Oceanic Administration: The specification for marine monitoring (Ocean Press, Beijiang 1991), p.205-282. (in Chinese) 